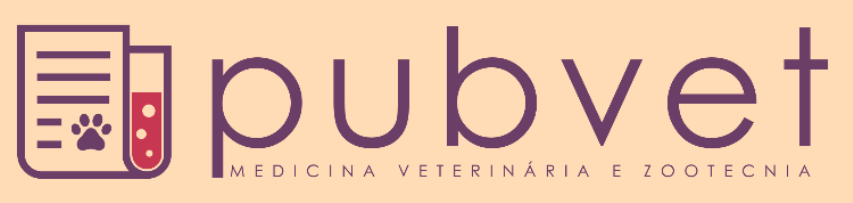

https://doi.org/10.31533/pubvet.v13n7a370.1-6

\title{
A organização dos testículos
}

\author{
Danillo Velloso Ferreira Murta ${ }^{* *}$, Daniele Carolina Rodrigues Xavier Murta ${ }^{2}$, Rodrigo Brito de

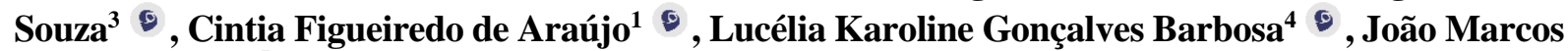 \\ Leite Santos ${ }^{5}$, Matheus Gonçalves Costa ${ }^{6}$, Lorena Augusta Marques Fernandes ${ }^{6}$, Patryssa

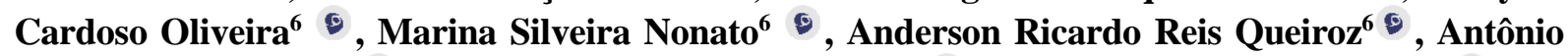 \\ Ray Amorim Bezerra $^{60}$, Vitória Cotrim Souza Figueredo ${ }^{60}$, Raquel Geovana Nunes Alves ${ }^{60}$
}

${ }^{1}$ Doutor(a). Docente do Curso de Medicina Veterinária do Centro Universitário UniFG, Guanambi, Bahia, Brasil. ${ }^{2}$ Médica Veterinária Autônoma graduada na Faculdades Integradas do Norte de Minas - Funorte, Montes Claros, Minas Gerais, Brasil ${ }^{3}$ Mestrando. Docente do Curso de Medicina Veterinária do Centro Universitário UniFG, Guanambi, Bahia, Brasil ${ }^{4}$ Mestre. Docente do Curso de Medicina Veterinária do Centro Universitário UniFG, Guanambi, Bahia, Brasil ${ }^{5}$ Mestrando. Departamento de Cirurgia, Faculdade de Medicina Veterinária e Zootecnia, Universidade de São Paulo, São Paulo, Brasil ${ }^{6}$ Acadêmico. Graduando Medicina Veterinária no Centro Universitário UniFG, Guanambi, Bahia, Brasil *Autor para correspondência, E-mail: danillo.murta.vet@gmail.com

Resumo. O testículo é um órgão com função exócrina, relacionada com a produção, armazenamento e transporte de espermatozoides, e função endócrina relacionada com a produção de hormônios andrógenos como a testosterona. É subdividido em dois compartimentos - tubulares e inter-tubulares - compostos por tipos celulares que desempenham funções distintas. Dentre as células que compõem a gônada masculina, destacam-se as células germinativas, que originarão os espermatozoides; as células de Sertoli e as células de Leydig. O objetivo desta revisão é descrever as características estruturais dos testículos, dos tipos celulares que o compõe e as suas respectivas funções.

Palavras chave: células germinativas, espermatozóide, sertoli. leydig, testículo

\section{Organization of the testis}

Abstract. The testis is an organ with exocrine function, related to production, storage and transport of sperm and endocrine function related to the production of androgen hormones like testosterone. It is divided into two compartments - intertubular and tubular - composed of cell types that perform different functions. Among the cells that make up the male gonad, we highlight the germ cells, which result in the sperm, the Sertoli cells and Leydig cells. The aim of this review is to describe the structural features of the testes, the cell types that comprise and their respective functions.

Key word: germ cells, sperm, sertoli, leydig, testis

\section{La organización de los testículos}

Resumen. El testículo es un órgano con función exocrina, relacionada con la producción, almacenamiento y transporte de espermatozoides, y función endocrina relacionada con la producción de hormonas andrógenos como la testosterona. Se subdivide en dos compartimentos - tubular e intertubular - compuestos por tipos celulares que desempeñan funciones distintas. Entre las células que componen la gónada masculina, se destacan las células germinativas, que originarán los espermatozoides; las células de Sertoli y las células de Leydig. El objetivo de esta revisión es describir las características estructurales de los testículos, de los tipos celulares que lo componen y sus respectivas funciones.

Palabras clave: células germinativas, espermatozoides, sertoli. leydig, testículo 


\section{Introdução}

Os testículos são órgãos pares contidos geralmente na cavidade do escroto. São responsáveis pela gametogênese e pela secreção dos hormônios sexuais masculinos, sobretudo a testosterona. Estruturalmente, os testículos estão envoltos por uma cápsula esbranquiçada de tecido conjuntivo, denominada túnica albugínea, que emite trabéculas até o mediastino dividindo-o incompletamente em lóbulos. A quantidade de tecido conjuntivo que forma estas trabéculas é variável entre as espécies de mamíferos eutérios (Russell et al., 1993).

Este órgão é subdividido em compartimentos tubular e intertubular, com predominância de tipos celulares distintos. O compartimento tubular é composto pelos túbulos seminíferos ou cordões testiculares; conjunto de túbulos em cujas paredes são encontradas as células germinativas em diferentes estágios de desenvolvimento, além das células de suporte - células de Sertoli (Grier, 1993). Já o compartimento intertubular é composto, sobretudo, pelas células de Leydig (Machado Junior et al., 2011). À medida que se desenvolvem, as células germinativas sofrem divisões e mudanças morfológicas, histoquímicas e bioquímicas até se caracterizarem como espermatozoides no lume dos túbulos seminíferos. As células de Sertoli regulam a espermatogênese e desempenham diversas funções na produção espermática. As células de Leydig, por sua vez, secretam o hormônio testosterona. O conhecimento da estrutura organizacional dos testículos é importante para o entendimento da fisiologia da gônada masculina, assim como para detecção de anormalidades.

\section{Testículos}

\section{Estrutura testicular}

A subdivisão dos testículos em dois compartimentos baseia-se em suas características morfológicas e funcionais. A distribuição das proporções volumétricas dos componentes testiculares é variável, o que pode refletir em diferenças na eficiência da espermatogênese nos mamíferos. O compartimento tubular representa de 70 a $90 \%$ do parênquima testicular dos mamíferos eutérios sexualmente maduros e apresenta grande influência sobre a produção espermática e o peso testicular (Belibasaki \& Kouimtzis, 2000; França et al., 2005; França \& Russell, 1998; Johnson et al., 1991; Russell et al., 1993). Este compartimento é formado por cordões testiculares ou túbulos seminíferos e encontra-se envolto pela túnica própria, que é composta por matriz extracelular e células mióides. Em seu interior, o epitélio seminífero possui células de suporte e células da linhagem germinativa em vários estágios de desenvolvimento (Castro et al., 1997; França \& Russell, 1998; Russell et al., 1993).

O número e as dimensões dos túbulos seminíferos diferem entre os mamíferos. Normalmente o diâmetro tubular é considerado um indicador da atividade espermatogênica, sendo constante em animais sexualmente maduros e não sazonais. No entanto, há diferenças entre as espécies e entre linhagens ou raças em uma mesma espécie, variando entre $180 \mu \mathrm{m}$ a $300 \mu \mathrm{m}$ nos mamíferos eutérios adultos (Schulz $\&$ Miura, 2002).

O peso dos testículos está relacionado, sobretudo com o comprimento total dos túbulos seminíferos que, consequentemente, depende do volume tubular, do diâmetro tubular e da proporção volumétrica dos túbulos seminíferos (Schulz \& Miura, 2002).

A altura do epitélio revela o grau de funcionalidade do túbulo seminífero (Courot et al., 1970) e seu valor varia entre 60 a $100 \mu \mathrm{m}$, para a maioria dos animais domésticos (França \& Russell, 1998). Embora ocorram variações entre as espécies, se observa que no espaço intertubular há predominância das células de Leydig em relação aos outros tipos celulares ou estruturas como vasos sanguíneos e linfáticos, nervos, células e fibras de tecido conjuntivo, macrófagos e mastócitos (Castro et al., 1997; França \& Russell, 1998; Russell et al., 1993).

\section{As células germinativas}

Os gonócitos são as primeiras células germinativas identificadas nos cordões testiculares, principalmente próximos à membrana basal. Morfologicamente, caracterizam-se por apresentar citoplasma claro e núcleo grande. O núcleo é arredondado a ovoide com cromatina frouxa e apresenta de um a quatro nucléolos (Aponte et al., 2005; Assis-Neto et al., 2003; Godinho \& Cardoso, 1979; 
Thomas \& Raja, 1980). Estas células primordiais se multiplicam e diferenciam em espermatogônias classificadas em tipo A, intermediárias e tipo B. A classificação é feita com base na morfologia, diâmetro e volume nuclear, número de nucléolos, disposição dos cromossomos durante a divisão e posição topográfica em relação às outras células e à lâmina basal (Guraya \& Bilaspuri, 1976). Embora distinções claras entre os tipos de espermatogônias tenham sido feitas em diversos mamíferos, tal diferenciação pode ser mais difícil em outras espécies (Clermont, 1972). Em geral, as espermatogônias tipo A apresentam núcleo volumoso e ovoide, com grânulos de cromatina dispostos irregularmente no nucleoplasma e presença de um a três nucléolos (Aponte et al., 2005; Assis-Neto et al., 2003). Os núcleos das espermatogônias intermediárias e tipo B reduzem de tamanho progressivamente, tornando-se mais esféricos até surgir a última geração desta célula (Courot et al., 1970).

A última geração espermatogonial, composta pelas espermatogônias $\mathrm{B}$, sofre divisão mitótica formando os espermatócitos primários. Em seguida, estes entram na primeira divisão meiótica formando os espermatócitos secundários. Posteriormente, ocorre a segunda divisão meiótica que origina as espermátides arredondadas. Estas se diferenciam em espermátides alongadas e, em seguida, em espermatozoides (Aponte et al., 2005; Courot et al., 1970; Evans et al., 1996; Guraya, 1987; Russell \& França, 1995).

Os espermatócitos primários são identificados inicialmente em pré-leptóteno, distribuídos em fileiras próximas à membrana basal. Nesta fase, apresentam núcleo arredondado contendo grânulos de cromatina que mascaram o nucléolo. Posteriormente, os espermatócitos assumem morfologia da fase de leptóteno da primeira divisão meiótica e se dispõem pouco mais afastados da membrana basal. Apresentam núcleos arredondados contendo grânulos de cromatina que se tornam filamentosos, formando novelos irregulares (Aponte et al., 2005; Assis-Neto et al., 2003; Clermont, 1972; Guraya, 1987). Os espermatócitos primários passam pela fase Zigóteno, caracterizada pelo pareamento dos cromossomos homólogos. Já na fase Paquíteno, dispõem-se distantes da membrana basal e sofrem aumento progressivo do volume nuclear, apresentando-o arredondado e com compactação dos cromossomos formando filamentos (Aponte et al., 2005; Assis-Neto et al., 2003). A seguir, uma curta fase Diplóteno é identificada, na qual apresentam tamanho nuclear máximo em comparação a outros espermatócitos. Tal fase caracteriza-se pela dispersão dos cromossomos, formação de tétrades entre cromossomos homólogos e pela separação parcial destes. Em seguida, o núcleo passa por Metáfase, Anáfase e Telófase da primeira divisão meiótica. Os espermatócitos secundários resultantes da divisão apresentam núcleo menor que os espermatócitos primários em Paquíteno. Estes entram em segunda divisão meiótica resultando na formação de espermátides haplóides (Guraya, 1987). As espermátides arredondadas formam camadas na metade luminal do epitélio seminífero e apresentam núcleo também arredondado, pequeno e claro (Aponte et al., 2005; Assis-Neto et al., 2003). Estas células sofrem alterações citoplasmáticas e nucleares alterando sua forma e originando as espermátides alongadas e os espermatozoides (Courot et al., 1970).

\section{As células de Sertoli}

As células de Sertoli são elementos somáticos que se localizam próximo à membrana basal dos túbulos seminíferos e se comunicam com células adjacentes por junções intercelulares. Também conhecidas como células suporte são responsáveis pela formação da barreira hematotesticular que separa o epitélio seminífero em compartimento basal e adluminal (Russell et al., 1993). Estas células favorecem o desenvolvimento do processo espermatogênico por fornecer suporte estrutural e aporte nutricional às células germinativas. Atuam também na fagocitose das células em degeneração e dos corpos residuais formados durante a espermiação. Além disso, contribuem com a liberação dos espermatozoides na luz dos túbulos seminíferos e com a secreção de fluidos para a formação do lume tubular, condução dos espermatozoides até o epidídimo e para a maturação espermática (Marina, 2003; Russell \& Clermont, 1977). Após o nascimento, a população das células indiferenciadas de suporte aumenta. Esse aumento ocorre até que se estabilizem as divisões e as células se diferenciem em células de Sertoli maduras. Morfologicamente, são células mais complexas por apresentar um núcleo irregular ou piramidal, com nucléolo evidente e comprimento variável - geralmente perpendicular à membrana basal e alongado em direção ao lume tubular (Aponte et al., 2005; Assis-Neto et al., 2003; Gondos \& Berndtson, 1993), o citoplasma normalmente é pouco corado e com limites pouco precisos. Com o avanço da idade ocorre 
aumento significativo do tamanho das células de Sertoli, resultante do alongamento do núcleo e da expansão do citoplasma (Aponte et al., 2005; Assis-Neto et al., 2003; Gondos \& Berndtson, 1993). O aumento do volume citoplasmático é influenciado principalmente pela quantidade de mitocôndrias, retículo endoplasmático e lisossomos, além da proliferação do citoplasma apical com o desenvolvimento do lume tubular (Gondos \& Berndtson, 1993). O percentual ocupado por estas células no parênquima testicular é variável entre as espécies. Ainda assim, há uma correlação fortemente negativa entre a proporção volumétrica destas células e a produção espermática. Portanto, não é ideal um percentual muito elevado das mesmas no parênquima (França \& Russell, 1998).

As células de Sertoli apresentam papel importante na regulação da espermatogênese, já que promovem a sustentação das células espermáticas. O número de células de Sertoli correlaciona-se positivamente com o peso testicular, com o número de diferentes populações de células germinativas e com a produção de espermatozóides (Berndtson \& Jones, 1989). Assim, a capacidade funcional das células de suporte é considerada um importante indicador da eficiência da produção espermática, pois cada célula de Sertoli é capaz de suportar um número limitado de células germinativas, numa determinada espécie (França et al., 2005; França \& Russell, 1998; Russell et al., 1993).

Durante o amadurecimento das células de suporte, ocorre o estabelecimento de projeções citoplasmáticas e uniões entre pontos da membrana plasmática, denominadas junções de oclusão. Estas junções são importantes para a formação da barreira hematotesticular e para a compartimentalização do epitélio, dividindo-o em basal e adluminal (Marina, 2003; Russell et al., 1993). O compartimento adluminal é adequado para a evolução do processo espermatogênico, visto que não sofre interferências externas diretas. No entanto, a barreira hematotesticular o torna dependente em relação ao acesso de nutrientes e hormônios. Assim, para alcançar este microambiente, qualquer substância precisa ser transportada ou secretada pela própria célula de Sertoli (Marina, 2003; Russell et al., 1993).

\section{As células Leydig}

As primeiras células de Leydig se desenvolvem durante a fase fetal e são responsáveis pela secreção de testosterona e consequente masculinização do sistema urogenital. Após o nascimento, a produção hormonal por estas células é responsável pelo desenvolvimento da atividade espermatogênica e manutenção da função reprodutiva. As células de Leydig, assim como as células de Sertoli, apresentam um padrão de proliferação próprio de cada espécie. Com a maturidade, as células de Leydig adultas diferenciadas cessam a proliferação e passam a constituir uma população de células estáveis. Em caso de morte, as mesmas são substituídas pela proliferação e diferenciação de células-tronco mesenquimais (Lejeune et al., 1998). Morfologicamente, a célula de Leydig apresenta núcleo excêntrico no citoplasma e, geralmente, de forma arredondada a ovoide (Hafez \& Hafez, 2004). Caracterizam-se pela presença de uma heterocromatina associado ao envelope nuclear (De Krester, 1994), assim como por apresentar grande quantidade de Retículo Endoplasmático Liso (REL).

O grande volume do REL correlaciona-se com a capacidade funcional desta célula em secretar testosterona. (França \& Russell, 1998). Em células de Leydig de ratos, o REL ocupa cerca de 39\% do citoplasma (Kerr et al., 1979), além de possuir sítios de ligação em sua superfície para uma grande variedade de enzimas que agem na conversão esteroidogênica. A secreção de testosterona pelas células de Leydig também é influenciada pela quantidade de LH disponível, pelo número de receptores de LH por célula, pela velocidade em que a testosterona deixa o testículo via vasos linfáticos, vasos sanguíneos e fluidos seminal, pelo volume sanguíneo do animal e pela taxa de metabolismo da testosterona (Lejeune et al., 1998).

\section{Considerações finais}

A partir do conhecimento da morfologia da gônada masculina pode-se compreender a fisiologia da produção dos espermatozóides e da testosterona. Assim, é possível evidenciar a importância de cada tipo celular e detectar anormalidades que possam acometê-lo. As células germinativas passam por diversos estágios de desenvolvimento e dependem do suporte fornecido pelas células de Sertoli e do estímulo hormonal gerado pelas células de Leydig. 


\section{Referências bibliográficas}

Aponte, P. M., Rooij, D. G. \& Bastidas, P. (2005). Testicular development in Brahman bulls. Theriogenology, 64(6):1440-1455.

Assis-Neto, A. C., Carvalho, M. A. M., Melo, M. I. V., Miglino, M. A., Oliveira, M. F. \& Mariana, A. N. B. (2003). Fases do desenvolvimento e diferenciação testicular em cutias (Dasyprocta aguti) criadas em cativeiros. Brazilian Journal of Veterinary Research and Animal Science, 4071-79.

Belibasaki, S. \& Kouimtzis, S. (2000). Sexual activity and body and testis growth in prepubertal ram lambs of Friesland, Chios, Karagouniki and Serres dairy sheep in Greece. Small Ruminant Research, 37(1-2):109-113.

Berndtson, W. E. \& Jones, L. S. (1989). Relationship of intratesticular testosterone content of stallions to age, spermatogenesis, Sertoli cell distribution and germ cell-Sertoli cell ratios. Reproduction, 85(2):511-518.

Castro, A. C. S., Berndtson, W. E. \& Cardoso, F. M. (1997). Cinética e quantificação da espermatogênese: bases morfológicas e suas aplicações em estudos da reprodução de mamíferos. Revista Brasileira de Reprodução Animal, 21(1):25-34.

Clermont, Y. (1972). Kinetics of spermatogenesis in mammals: seminiferous epithelium cycle and spermatogonial renewal. Physiological Reviews, 52(1):198-236.

Courot, M., Hochereau-De Riviers, M. T. \& Ortavant, R. (1970). Spermatogenesis. In A. D. Johnson, Gomes W.R \& N. L. Vandemark (Eds.), The testis (pp. 339-432). New York, USA: Academic Press.

De Krester, D. M. (1994). The cytology of the testis. In E. Knobil \& J. D. Neill (Eds.), The physiology of reproduction (pp. 1177-1290). New York, USA: Raven Press Ltd.

Evans, A. C. O., Pierson, R. A., Garcia, A., McDougall, L. M., Hrudka, F. \& Rawlings, N. C. (1996). Changes in circulating hormone concentrations, testes histology and testes ultrasonography during sexual maturation in beef bulls. Theriogenology, 46(2):345-357.

França, L. R., Avelar, G. F. \& Almeida, F. F. L. (2005). Spermatogenesis and sperm transit through the epididymis in mammals with emphasis on pigs. Theriogenology, 63(2):300-318.

França, L. R. \& Russell, L. D. (1998). The testis of domestic animals. In J. Regadera \& F. MartinezGarcia (Eds.), Male reproduction. A multidisciplinary overview (pp. 197-219). Madrid, Espanha: Churchill Livingstone.

Godinho, H. P. \& Cardoso, F. M. (1979). Desenvolvimento sexual de porcos Yorkshire. II. Estabelecimento e evolução da espermatogênese. Arquivos da Escola de Veterinaria da Universidade Federal de Minas Gerais, 31(3):351-361.

Gondos, B. \& Berndtson, W. E. (1993). Postnatal and pubertal development. In L. D. Russell \& M. D. Griswold (Eds.), The sertoli cell (pp. 115-154): Clearwater: Cache River.

Grier, H. J. (1993). Comparative organization of Sertoli cells including the Sertoli cell barrier. The Sertoli Cell, 1703-739.

Guraya, S. S. (1987). Biology of spermatogenisis and spermatozoa in mammals. Berlin, Alemanha: Springer-Verlag.

Guraya, S. S. \& Bilaspuri, G. S. (1976). Stages of seminiferous epithelial cycle and relative duration of spermatogenic processes in the buffalo (Bos bubalus). Gegenbaurs Morphologisches Jahrbuch, 122(2):147-161.

Hafez, B. \& Hafez, E. (2004). Reprodução Animal (Vol. 1, pp. 513): Manole: São Paulo, Brasil.

Johnson, L., Varner, D. D. \& Thompson Junior, D. L. (1991). Effect of age and season on the establishment of spermatogenesis in the horse. Journal of Reproduction and Fertility, 44(Sup.):8797.

Kerr, J. B., Rich, K. A. \& Kretser, D. M. (1979). Alterations of the fine structure and androgen secretion of the interstitial cells in the experimentally cryptorchid rat testis. Biology of Reproduction, 20(3):409-422.

Lejeune, H., Habert, R. \& Saez, J. M. (1998). Origin, proliferation and differentiation of Leydig cells. Journal of Molecular Endocrinology, 20(1):1-26. 
Machado Junior, A. A. N., Assis Neto, A. C., Sousa Junior, A., Menezes, D. J. A., Alves, F. R., Sousa, A. L. \& Carvalho, M. A. M. (2011). Daily sperm production and testicular morphometry in goats according to external scrotal conformation. Animal Reproduction Science, 127(1-2):73-77.

Marina, S. (2003). Avances en el conocimiento de la espermatogénesis. Implicaciones clínicas. Revista Iberoamericana de Fertilidad, 20(4):213-225.

Russell, L. D. \& Clermont, Y. (1977). Degeneration of germ cells in normal, hypophysectomized and hormone treated hypophysectomized rats. The Anatomical Record, 187(3):347-365.

Russell, L. D., Ettlin, R. A., Hikim, A. P. S. \& Clegg, E. D. (1993). Histological and histopathological evaluation of the testis. International Journal of Andrology, 16(1):83-83.

Russell, L. D. \& França, L. R. (1995). Building a testis. Tissue and Cell, 27(2):129-147.

Schulz, R. W. \& Miura, T. (2002). Spermatogenesis and its endocrine regulation. Fish Physiology and Biochemistry, 26(1):43-56.

Thomas, U. P. \& Raja, C. K. S. V. (1980). Histological changes of epididymis during postnatal maturity in pigs. Kerala Journal of Veterinary Science, 2296-310.

Recebido: 13 de maio, 2019.

Aprovado: 13 de junho, 2019.

Publicado: 5 de agosto, 2019.

Licenciamento: Este artigo é publicado na modalidade Acesso Aberto sob a licença Creative Commons Atribuição 4.0 (CC-BY 4.0), a qual permite uso irrestrito, distribuição, reprodução em qualquer meio, desde que o autor e a fonte sejam devidamente creditados. 